\title{
Mechanisms and individual consequences of intraspecific competition in a coral-reef fish
}

\author{
Michael S. Webster*, Mark A. Hixon \\ Oregon State University, Department of Zoology, Corvallis, Oregon 97331-2914, USA
}

\begin{abstract}
Species of coral-reef fish that exhibit dominance hierarchies provide opportunities for experimental studies of intraspecific competition within discrete social groups. The fairy basslet Gramma loreto (Grammatidae) lives in dominance hierarchies that occupy the undersides of open reef ledges in the Caribbean region. Each hierarchy is maintained by aggression between size classes such that larger fish occupy prime plankton-feeding positions closer to the outer edge of the ledge. We conducted a removal experiment in the central Bahamas to determine the role of larger fish in maintaining the hierarchy and the resultant consequences to smaller fish. When larger fish were removed, smaller individuals quickly occupied these prime feeding positions and were the recipients of less aggression compared to controls. As a result, the average feeding rates of smaller fish were more than $60 \%$ higher in aggregations in which larger fish had been removed. Differences in feeding rates were the result of 2 types of competitive effects: between-position and within-position. The between-position effect was the result of differential feeding rates associated with different feeding positions within an aggregation. The within-position effect was due to interactions within a given feeding position. Although both effects strongly influenced basslet feeding rate, the magnitude of the within-position effect was roughly 3 times that of the between-position effect. Together, these 2 components of competition may affect demographic rates and ultimately contribute to lacal population regulation.
\end{abstract}

KEY WORDS: Coral-reef fish · Intraspecific competition · Dominance hierarchy

\section{INTRODUCTION}

The role of competition for limiting resources in the ecology of coral-reef fishes is controversial, and the prevailing view on the importance of competition has shifted historically (reviews by Ebeling \& Hixon 1991, Jones 1991). Before the mid-1970s most reef fish ecologists accepted the then dominant view of terrestrial ecologists that competition was ubiquitous and substantial (e.g., Smith \& Tyler 1972). By the mid-1980s, this conventional wisdom was overturned and the paradigm became that competition was unimportant. This view, the recruitment limitation hypothesis, asserted that larval supply is so low that populations rarely reach levels where resources become limiting (e.g., Doherty 1981, Doherty \& Williams 1988). Reviewing the empirical evidence, Jones (1991) noted that, even for territorial or obviously aggressive reef fishes, the

•E-mail: websterm@bcc.orst.edu role of interference competition in limiting adult numbers or structuring populations was uncertain. He concluded that the major effect of competition in general is to limit individual growth rates (Jones 1991).

In the past decade, evidence for ecological consequences of competition in reef fishes has increased, but has mostly involved territorial species. For example, Robertson (1996) demonstrated experimentally that interspecific competition affects the abundance and habitat use of territorial Caribbean damselfishes. Unlike competition between species, intraspecific competition may be most pronounced when individuals form social groups. Although membership in an aggregation may enhance feeding success and predator avoidance, intraspecific competition between group members for food or other resources may partially offset these benefits (Betram 1978, Rubenstein 1978, Mangel 1990, Pitcher \& Parrish 1993). Intraspecific competition may be manifest as size or dominance hierarchies, whereby the largest or most aggressive individuals utilize a greater proportion of a resource 
than smaller or subordinate individuals. Among reef fishes, dominance hierarchies have been documented primarily in several species of damselfish (e.g., Coates 1980, Doherty 1982, Shulman 1985, Forrester 1991 . Booth 1995).

Competitive hierarchies can occur when access to food resources is determined by relative position within a group. Among planktivorous coral-reef fishes, individuals may maintain relatively fixed positions in currents and feed on passing plankton (Hobson \& Chess 1978, Coates 1980, Booth 1991, Forrester 1991, Hobson 1991). This pattern is often explained in terms of predator avoidance, where feeding position is based on an individual's ability to reach shelter quickly as a predator approaches. Larger fish swim faster, so they can feed farther from the reef with no increase in the time required to reach shelter relative to smaller, slower fish that remain closer to the reef (Hobson \& Chess 1978, Hobson 1991).

The fairy basslet Gramma loreto (family Grammatidae) is a common coral-reef fish in the Caribbean and Bahamas (Bölhke \& Chaplin 1993). Basslets range in size from about $1.0 \mathrm{~cm}$ standard length (SL) at settlement to large adults about $7 \mathrm{~cm} \mathrm{SL} . G$. loreto are typically found oriented upside-down on the ceilings of open caves and ledges, where they feed on passing zooplankton (Randall 1967. Luckhurst \& Luckhurst 1977, Bolhke \& Chaplin 1993). This species occurs in size-structured aggregations, with the largest individuals near the front of an aggregation and progressively smaller individuals toward the back (Freeman \& Alevizon 1983). Within aggregations, the largest individuals chase smaller individuals, and each fish tends to remain within a restricted area (Freeman \& Alevizon 1983).

The goal of this study was to examine the competitive mechanisms that maintain size hierarchies, and the consequences of these hierarchies for small fish within Gramma loreto aggregations. Specifically, we examined the size structure of aggregations and the role of aggressive interactions in maintaining a sizebased dominance hierarchy. We hypothesized that feeding position was related to feeding rate, whereby individuals closer to the front of an aggregation have first access to planktonic food, depleting this resource and leading to depressed feeding rates for individuals toward the back of an aggregation. To test this hypothesis, we experimentally measured how feeding behavior of smaller individuals within an aggregation was affected by the removal of larger individuals. We measured 2 types of competitive effects: between-position and within-position. The between-position effect is manifest as differential feeding rates associated with different feeding positions within an aggregation. The within-position effect is due to interactions within a given feeding position. We assessed the relative mag- nitude of these 2 effects of competition and then determined the net costs to smaller individuals in terms of feeding rate.

\section{METHODS}

This study was conducted during August and September 1994 in an area of continuous coral reef $(6$ to $10 \mathrm{~m}$ deep) in the Exuma Keys, Bahamas, near the Caribbean Marine Research Station on Lee Stocking Island. Fourteen ledges (rock overhangs) were chosen based on their relatively large size, their isolation from other ledges, and the presence of Gramma loreto aggregations. Ledges were 1 to $2 \mathrm{~m}$ deep, ledge surface area ranged from 1.4 to $10.4 \mathrm{~m}^{2}$ and $G$. loreto aggregation size ranged from 17 to 71 individuals. Aggregation size was strongly related to ledge area (Webster unpubl. dataj. Because these ledges were not identical in terms of their area, size distributions or densities of fish, any patterns that were consistent across ledges were likely to be fairly general for a wide range of ledges.

Fish size and feeding position. On each ledge, we visually assigned each fish to a $1 \mathrm{~cm}$ SL size class for a total of 7 size classes $(1.0-1.9 \mathrm{~cm}, 2.0-2.9 \mathrm{~cm}$, etc. $)$ For our first survey, we used $0.5 \mathrm{~cm}$ size classes $(1.0-1.4 \mathrm{~cm}, 1.5-1.9 \mathrm{~cm}$, etc.). Periodic tests of the accuracy of visual censuses were conducted by estimating the size and then capturing individual fish. In every case, these fish could be estimated accurately within $0.5 \mathrm{~cm}$ of their actual length.

On each ledge, the feeding position of each Gramma loreto was measured on 3 consecutive days. Absolute feeding position was measured as the distance between a fish and the front of a ledge. Absolute position thus ranged from 0 , at the front of the ledge, to $0.8-1.7 \mathrm{~m}$ (the range observed) at the back of the ledge (Fig. 1). We standardized absolute position by calculating relative feeding position as 1 - (absolute position/ledge depth). This permitted us to make comparisons among ledges that were not influenced by differences in ledge size or shape. For example, a fish at the back of a small ledge could have had the same absolute position as a fish near the middle of a large ledge. The relative positions of these 2 fish better reflect their positions with respect to the dominance hierarchy at their home ledge.

Removal experiment. To examine the effects of larger Gramma loreto on smaller individuals, we conducted a controlled removal of larger fish. Each ledge was randomly assigned to 1 of 2 treatments: unmanipulated control ( $N=7$ ledges) and removal $(N=7$ ledges). On removal ledges, all fairy basslets $4 \mathrm{~cm}$ SL or larger were removed by divers using hand nets and 
the anaesthetic quinaldine. To maintain statistical independence, ledges were treated as experimental units $_{\text {; }}$ therefore, throughout the analysis we combined multiple measurements taken from a given ledge into a single mean response for that ledge. The statistical comparisons throughout the analysis were directional (except when comparing regression slopes between treatments), thus we examined 1 -tailed p-values. However, for completeness, we also calculated 2-tailed pvalues. Using 1 -tailed tests affected only 1 of our conclusions: that regarding the location of aggressive interactions (see 'Results'). During the experiment, we made comparative observations of aggressive interactions, feeding positions and feeding rates.

Aggressive interactions: Aggressive interactions were observed on each ledge for $3 \mathrm{~d}$. Each day, all chases between individuals on each ledge were noted during a 6 min observation period conducted during midday. We recorded absolute position at the initiation of the interaction as well as the size class of the aggressor (individual chasing) and the recipient (individual being chased). We used these estimates to compare how the relative frequency of aggressive interactions varied with fish size and experimental treatment, and to determine whether the chase frequency rate of small fish (1, 2, and $3 \mathrm{~cm}$ SL) varied on control and fishremoval ledges.

To determine whether smaller fish were chased more often when they were closer to the front of a ledge, we calculated relative position chased for size classes $2,3,4$, and $5 \mathrm{~cm}$ SL for each control ledge (size classes 1,6 , and $7 \mathrm{~cm}$ SL were not used due to small sample sizes; $N=1,3$ and 0 respectively). This value was then subtracted from the average feeding position (from the initial survey) for these size classes on each control ledge. Values from each size class were then averaged for each ledge, providing a single measurement describing where individuals were chased relative to where they were typically found. Values greater than zero indicated that fish were chased more frequently than average when they were closer to the front of a ledge.

Feeding position: Following the removal of larger basslets, the absolute feeding position of all remaining fish on each ledge was again measured on 3 subsequent dates. We converted these measurements to the average relative feeding position for each size class for each ledge. Pre-removal feeding position was then subtracted from post-removal position for size classes 1,2 and $3 \mathrm{~cm} \mathrm{SL}$. These values were then averaged, providing a single value describing any change in feeding position for each ledge.

Feeding rate: To examine the effects of larger fish on the feeding rates of smaller fish, we compared feeding rates of small fish on control and removal ledges. Focal

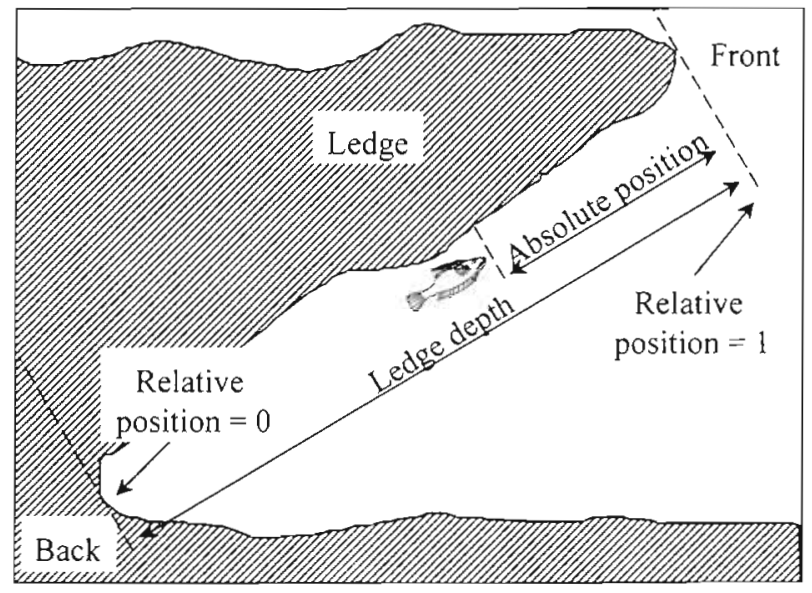

Fig. 1. Feeding positions of Gramma loreto on a typical reef ledge. Relative position $=1-$ (absolute position/ledge depth) . Therefore, relative position equals 1 at the front of a ledge and 0 at the back

fish feeding rates (sensu Forrester 1991) were observed for $3 \mathrm{~cm}$ SL basslets on each ledge on $3 \mathrm{~d}$. Feeding was defined as bites directed at planktonic organisms in the water column. On each occasion, feeding rate was measured for 4 individuals distributed throughout each ledge (for a total of 12 observations per ledge). Individuals were chosen to represent the full range of possible feeding positions. Each ledge was roughly divided into 4 sections (front, front-mid, back-mid, and back), and 1 individual was chosen haphazardly from each of these 4 sections for observation. When no individuals were present in a given section, the closest individual in a neighboring section was observed. Once an individual was chosen, its absolute position was recorded, and a diver observed its feeding frequency for 1 to 2 min.

To combine individual feeding rate measurements within a given ledge into a single parameter, we fit simple linear regression models (feeding rate as a function of relative position) separately for each ledge. Because there was a positive linear relationship between feeding position and feeding rate, a simple ledge average would not accurately describe all feeding rates on a given ledge. Therefore, we used the slopes as our parameter to test whether the relationship between feeding rate and relative position varied between treatments, i.e., an interactive treatment effect. Note that if there were no differences in slope a difference in the intercept would indicate an additive treatment effect.

We then used the linear regression models to estimate feeding rates for each treatment. From each regression model, we calculated point estimates of feeding rate at various feeding positions. The 7 resulting estimates of feeding rate per treatment 11 from 
each ledge) were then used to estimate mean feeding rate and variance for a given feeding position. Note that the confidence intervals (CI) reported are based on the variance in our point estimates, not the variance in individual measurements of feeding rate at that position. By using average regression parameters, we constructed linear estimates of the relationship between feeding rate and feeding position for control and removal ledges.

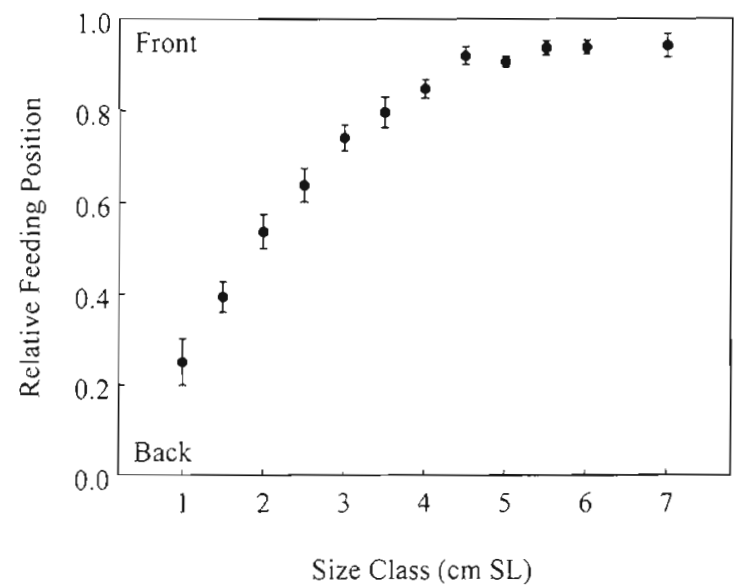

Fig. 2. Relative feeding position $(\bar{x} \pm \mathrm{SE})$ of each size class of Gramma loreto. Error bars are based on mean position measurements from each ledge ( $N=14$ ledges). SL: standard length

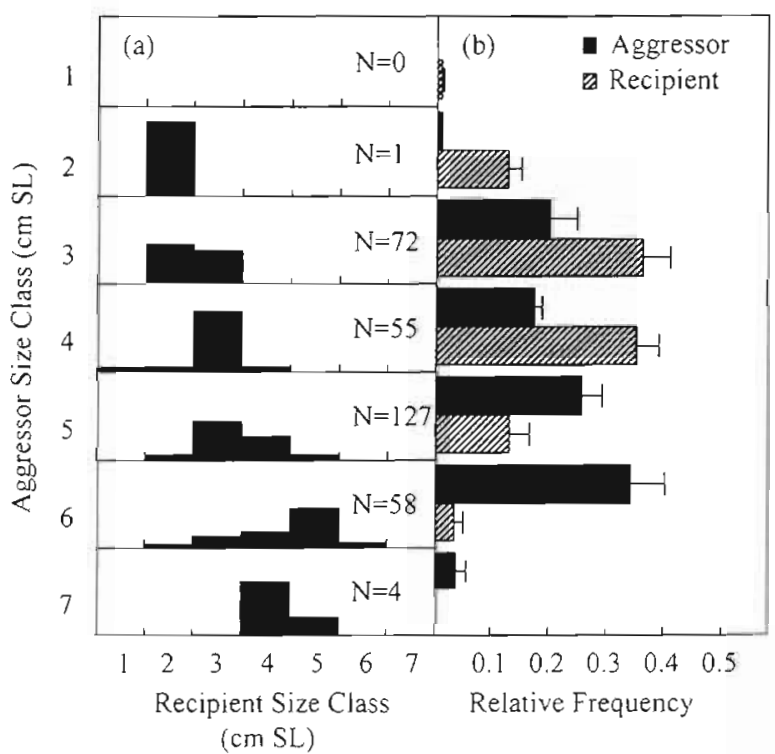

Fig. 3. Aggression between size classes of Gramma loreto on control ledges. (a) Each plot is the relative frequency of $\mathrm{N}$ chases by a single size class (aggressor) directed toward each size class (recipient). For each plot, the total area of the bars equals 1 (except for size class 1 , which was never observed as an aggressorj. (b) The relative irequency at which each size class acted as an aggressor and as a recipient of aggression $[\vec{X} \pm \mathrm{SE}, \mathrm{N}=7$ ledges each)

\section{RESULTS}

\section{Fish size and feeding position}

There was a strong relationship between fish size and relative feeding position on a ledge (Fig. 2). Individuals larger than approximately $5 \mathrm{~cm}$ SL were more likely to be found near the front of the ledge. Below $5 \mathrm{~cm}$, feeding position decreased dramatically with decreasing individual size.

\section{Removal experiment}

\section{Aggressive interactions}

Aggressive interactions were strongly size-dependent. During every observed aggressive interaction, the aggressor was the same size or larger than the recipient (Fig. 3a). Virtually all aggression was directed toward fish of the same size as the aggressor or of the next smaller size class. Nearly all aggressive interactions were directed toward fish smaller than $5 \mathrm{~cm} \mathrm{SL}$; the majority were toward 3 and $4 \mathrm{~cm}$ fish. Three to $6 \mathrm{~cm}$ fish were the most frequent aggressors. Between 4 and $5 \mathrm{~cm} \mathrm{SL}$, fish shifted from being primarily recipients to being primarily aggressors (Fig. 3b).

Aggressive interactions tended to occur when fish were further forward on a ledge than their average feeding position (Fig. 4). While not statistically significant $\left(1\right.$-tailed paired $t$-test: $\left.t_{6}=1.80, p=0.063\right)$, this trend was consistent for all size classes.

The frequency at which $3 \mathrm{~cm}$ SL fish received aggression was significantly higher on control ledges than on ledges where larger fish had been removed

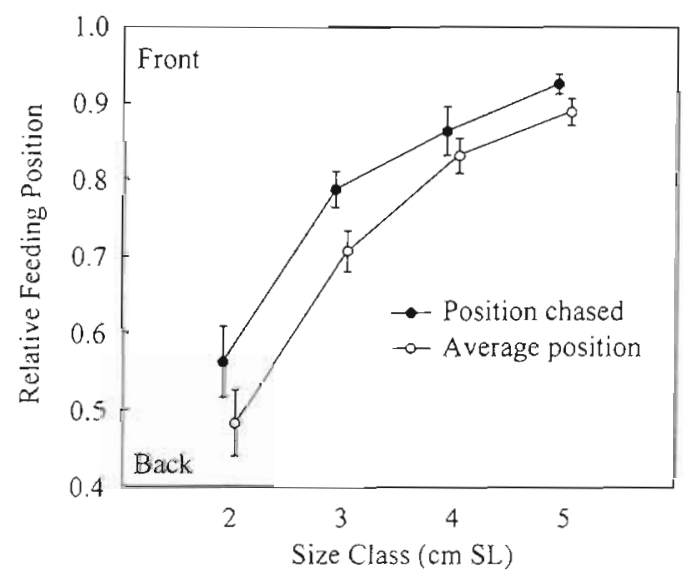

Fig. 4. Average relative feeding position, and relative position when chased, for each size class of Gramma loreto on control ledges $(\vec{X} \pm S E, N=7$ ledges each). Points are offset to clarify error bars 


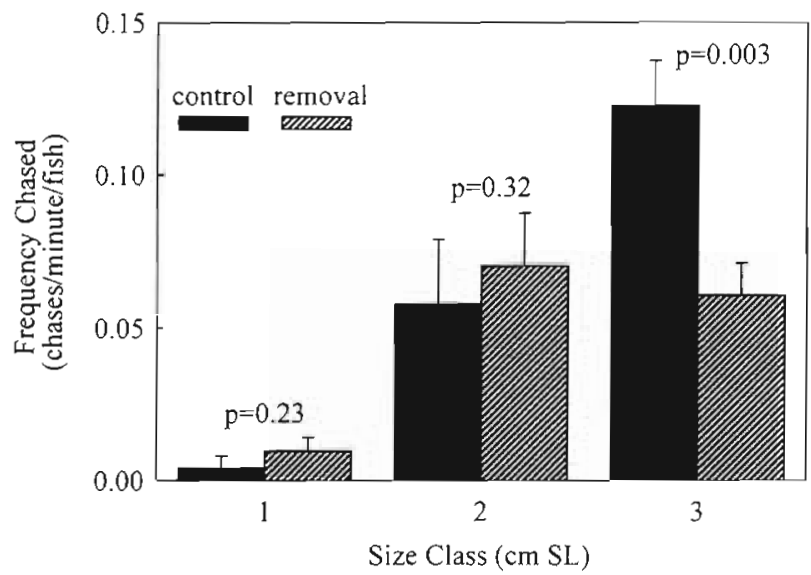

Fig. 5. Frequency of aggressive interactions directed toward smaller size classes of Gramma loreto on control and removal ledges $(\bar{x}+\mathrm{SE}, N=7$ ledges each $)$

(Fig. 5, 1-tailed $t$-test: $t_{12}=3.42, \mathrm{p}=0.003$ ). The $3 \mathrm{~cm}$ fish were recipients of aggression more than twice as frequently on control ledges than on removal ledges. There was no difference between treatments for 1 or $2 \mathrm{~cm}$ fish (1-tailed t-test: $t_{12}=-0.74, \mathrm{p}=0.23$ for $1 \mathrm{~cm}$ fish and $t_{12}=-0.46, \mathrm{p}=0.32$ for $2 \mathrm{~cm}$ fish).

\section{Feeding position}

Fish $3 \mathrm{~cm}$ SL and smaller moved forward on ledges following the removal of larger fish (Fig. 6a, 1-tailed paired $t$-test: $\left.t_{6}=3.55, \mathrm{p}=0.006\right)$. On average, the fish remaining on removal ledges moved forward $11 \%$ of the ledge depth $(95 \% \mathrm{CI}: 3$ to $17 \%, \mathrm{~N}=7) ; 3 \mathrm{~cm}$ fish, in particular, moved forward $14 \%(95 \%$ CI: 9 to $23 \%$, $\mathrm{N}=7$ ). All remaining fish continued to maintain distinct size segregation (Fig. 6a). There was no evidence of any movement forward for fish $3 \mathrm{~cm}$ and smaller on control ledges (Fig. 6 b, 1-tailed paired $t$-test: $t_{6}=1.27$, $\mathrm{p}=0.13$ ).

\section{Feeding rate}

The slope of the relationship between feeding rate and relative feeding position differed between control and removal ledges (2-tailed $t$-test: $t_{12}=2.89, \mathrm{p}=$ $0.014)$. The slope estimates were positive for all aggregations, indicating that feeding rate invariably increased with distance toward the front of the ledge. For both treatments, average slope values were significantly larger than zero (1-tailed $t$-test: $t_{6}=8.42$, $\mathrm{p}<0.0001$ for control and $t_{6}=13.36, \mathrm{p}<0.0001$ for removal).

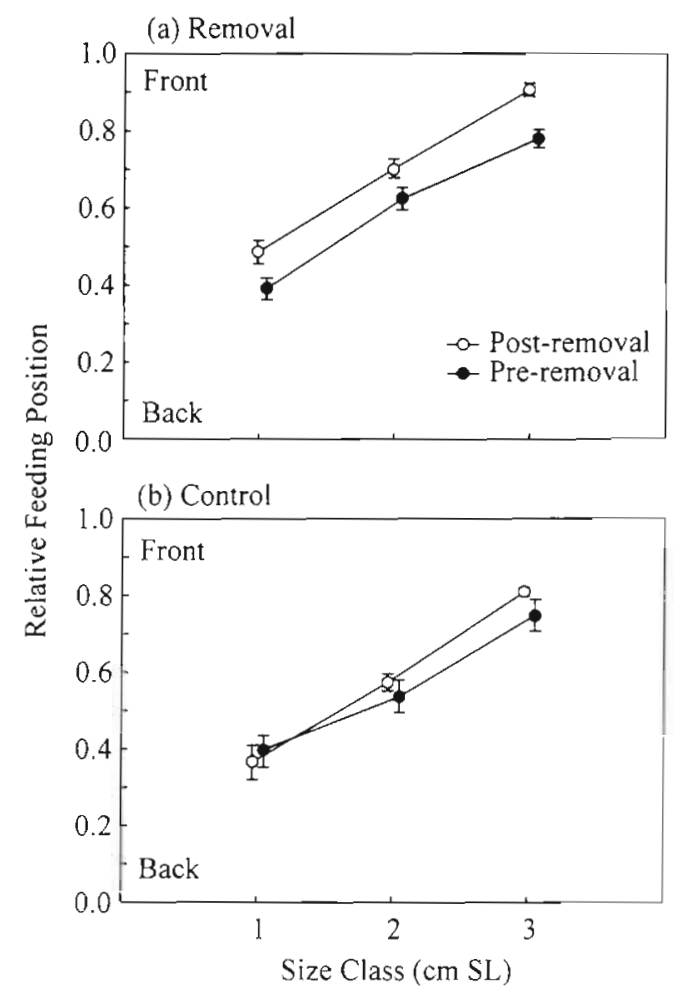

Fig. 6. Relative feeding position $(\bar{x} \pm S E, N=7$ ledges each $)$ of smaller size classes of Gramma loreto before and after removal of larger fish on (a) removal ledges versus (b) unmanipulated control ledges. Points are offset to present error bars clearly

We used the regression results to estimate feeding rate for $3 \mathrm{~cm}$ fish in each treatment. We estimated the between-position effect of competition on feeding rate by calculating the change in feeding rate associated with movement forward on a ledge. By moving forward $14 \%$ of the ledge depth (as was observed for $3 \mathrm{~cm}$ fish), the average feeding rate of a $3 \mathrm{~cm}$ fish increased an estimated 0.62 bites min $^{-1}$ (Fig. 7, 95\% CI: 0.28 to 1.22 bites $\min ^{-1}, N=7$ ). We also used regression point estimates to evaluate the withinposition effect by calculating the difference in feeding rate between control and removal ledges. At the average post-removal feeding position of $3 \mathrm{~cm}$ fish on removal ledges, feeding rate was estimated to be 2.12 bites min $^{-1}$ greater on removal ledges than on control ledges (Fig. 7, 95\% CI: 1.17 to 3.07 bites min $^{-1}, N=14$ ). Considering both increased feeding rates within a position $\left(2.12\right.$ bites $\left.\mathrm{min}^{-1}\right)$, and increased feeding rate between positions $(0.62$ bites $\mathrm{min}^{-1}$ ), an average $3 \mathrm{~cm}$ fish on a removal ledge fed an estimated 2.74 bites $\min ^{-1}$ (95\% CI: 1.86 to 3.62 bites $\left.\mathrm{min}^{-1}, \mathrm{~N}=14\right)$ or $63 \%(95 \% \mathrm{CI}: 43$ to $84 \%, \mathrm{~N}=$ 14) more frequently than an average $3 \mathrm{~cm}$ fish on a control ledge (Fig. 7). 


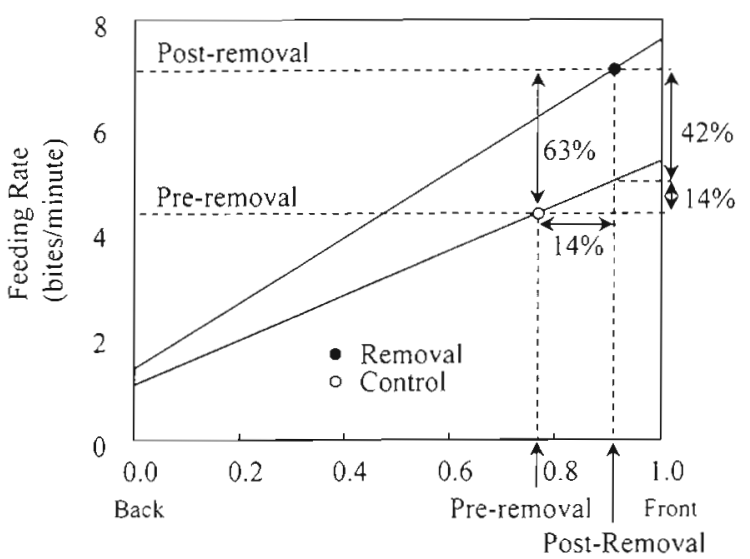

Relative Feeding Position

Fig. 7 Average change in feeding position and difference in feeding rate for $3 \mathrm{~cm}$ Gramma loreto, after experimental removals of larger fish, relative to unmanipulated controls. Control and removal regression lines are each based on the average parameters from 7 aggregations ffor control ledges feeding rate $=1.36+6.26$ [feeding position]; for removal ledges feeding rate $=1.05+4.28$ [feeding position]). On average, $3 \mathrm{~cm}$ fish were $14 \%$ closer to the front of a ledge after the removal of larger fish. Moving this distance on a control ledge is estimated to have resulted in a $14 \%$ increase in feeding rate (between-position effect). However, at the mean postremoval position, individuals on removal ledges were estimated to feed $42 \%$ more frequently than on control ledges (within-position effect). The net result is an average increase of $63 \%$ in the feeding rate of $3 \mathrm{~cm}$ fish on ledges where larger fish were removed

\section{DISCUSSION}

Dominance hierarchies provide opportunities to examine experimentally the mechanisms and consequences of intraspecific competition in reef fish (e.g., Coates 1980, Forrester 1991, Booth 1995). We measured the magnitude of intraspecific competition in basslets directly in terms of effects on feeding rate, as well as the relative contribution of 2 different components of competition. Reduced feeding rate of smaller fish was caused by larger, dominant individuals. Similar patterns may be widespread in fishes where dominance is often a function of size and related to foraging success (e.g., Coates 1980, Koebele 1985, Forrester 1991, Robertson 1998). For example, Coates (1980) and Forrester (1991) found that the feeding rate of a damselfish Dacyllus aruanus was partially determined by individual position within an aggregation, which in turn was related to individual size. The largest, most dominant individuals tended to remain at the up-current edge of the aggregation, presumably acquiring first access to planktonic food. Koebele (1985) observed that dominant cichlids consumed a greater proportion of available prey, thereby exploitatively de- pressing the food supply of subordinates. Further, dominant individuals behaviorally inhibited the feeding rate of subordinates. Jenkins (1969) observed that, like basslets, feeding position among stream salmonids was determined by social dominance. When dominant individuals were removed, subordinate individuals quickly occupied the vacant feeding positions

Within fairy basslet aggregations, we found a strong relationship between individual size and feeding position on a ledge: larger fish were closer to the front of the ledge, where they apparently had first access to passing planktonic food. Our results indicate that aggressive interactions maintained this relationship through a rigid dominance hierarchy. Consequently, smaller fish were prevented from moving forward, thus reducing crowding at a given feeding position on a ledge. However, individuals larger than $4 \mathrm{~cm} \mathrm{SL}$ were typically at the front of the ledge. The range of 4 to $5 \mathrm{~cm}$ SL appeared to be a transitional size, where fish switched from being primarily subject to aggression to being aggressors. This is roughly the size at which individuals become reproductively mature (Asoh 1992). Therefore, it appears that aggressive interactions prevent individuals from gaining access to the front of the ledge until they are adults.

We observed a decrease in the frequency of aggressive interactions after larger fish were experimentally removed. However, a decrease was evident only for $3 \mathrm{~cm}$ fish, not for 1 or $2 \mathrm{~cm}$ fish. This is consistent with observations that individuals usually chase fish of equal size or 1 size class smaller. When all fish were present, 3,4 and $5 \mathrm{~cm}$ fish were the primary aggressors towards $3 \mathrm{~cm}$ fish. Removals of fish $4 \mathrm{~cm}$ and larger eliminated the between-size-class component of aggressive interactions, leaving only within-size-class effects. As a result, $3 \mathrm{~cm}$ fish were chased far less frequently where larger fish were removed. The frequency at which 1 and $2 \mathrm{~cm}$ fish were chased did not differ between control and removal ledges because the size classes most frequently aggressive towards these individuals ( 2 and $3 \mathrm{~cm}$, respectively) remained after the removal of $4 \mathrm{~cm}$ and larger fish

After the removal of larger fish, smaller fish moved toward the front of the ledge, a pattern that was not observed on control ledges. The removal of larger fish facilitated forward movement by eliminating betweensize-class aggression directed towards $3 \mathrm{~cm}$ fish. This shift, in turn, permitted the forward movement of 1 and $2 \mathrm{~cm}$ fish behind the $3 \mathrm{~cm}$ fish. Size segregation was maintained for these individuals because the betweensize-class component of competition was not reduced for 1 and $2 \mathrm{~cm}$ fish. This pattern further supports the hypothesis that an individual's position on a ledge is determined by aggressive interactions between size classes. 
The behavioral interactions observed between fairy basslets imply that maintaining a position near the front of a ledge affords some advantage and that crowding at a given position results in a disadvantage. Our results implicate intraspecific competition for feeding positions as the driving force behind these patterns. Intraspecific competition in fairy basslet aggregations is probably a consequence of their feeding mode. Basslets maintain relatively fixed positions under ledges and feed on passing plankton (Randall 1967, Luckhurst \& Luckhurst 1977, Bölhke \& Chaplin 1993). Water masses containing relatively abundant zooplankters are likely to first pass the front of a ledge via surge or tidal currents in the same way that they first pass reef edges (Hobson \& Chess 1978, Hobson 1991). As the water moves toward the back of the ledge, zooplankters are probably depleted by the largest basslets (see Coates 1980, Forrester 1991). This situation likely creates a gradient of decreased food abundance towards the back of the ledge. Consistent with our results, such a pattern would create an advan. tage for individuals near the front of the ledge and an incentive to prevent others from moving forward.

We measured 2 effects of intraspecific competition, between and within feeding positions. The betweenposition effect is the result of differential feeding rates based on an individual's distance from the front of a ledge. Such an effect is likely a result of depletion of food by larger fish that aggressively deny smaller fish access to the front of a ledge. The within-position effect is due to interactions between larger fish and smaller fish at a given position on a ledge. Thus both between-position and within-position effects can involve both non-aggressive exploitative and aggressive interference competition (sensu Schoener 1983).

Although both components strongly affected basslet feeding rate, the magnitude of the within-position effect was roughly 3 times that of between-position effect. This result indicates that the competitive effect of larger fish is due mostly to aggressively reducing the feeding rates of smaller fish at a given position rather than preventing smaller fish from moving their feeding positions forward on a ledge. However, smaller fish are not likely to be able to reduce the within-position effect, whereas they may be able to reduce the between-position effect. A reduction in the within-position effect would require a reduction in the number of larger fish toward the front of a ledge. A smaller fish could accomplish this only by emigrating to a ledge with a lower density of larger fish. However, the habitat requirements of basslets are quite specific (Randall 1967, Luckhurst \& Luckhurst 1977, Bölhke \& Chaplin 1993) and suitable habitat is patchy. Consequently, emigrating individuals would need to cross considerable distances to find suitable habitat of uncertain quality, all the while being relatively vulnerable to predation. In fact, emigration is rare (Webster unpubl. data). It appears to be more advantageous for individuals to remain on a ledge in the presence of strong competition than to risk predation and uncertain habitat quality associated with emigration.

Unlike the within-position effect, individual basslets may reduce the between-position effect simply by moving toward the front of a ledge. Such movement explains our behavioral observations. It appears that smaller fish consistently initiated movements toward the front of a ledge, thereby gaining access to greater food availability. At the same time, larger fish prevented this movement, thereby monopolizing passing prey. It is unclear whether fish simply move forward as they grow larger or if fish that maintain better feeding positions grow faster. Growth and change in position are likely a combination of these 2 processes.

The effects of intraspecific competition on small basslet feeding rates were large: in the absence of both components of intraspecific competition, the average feeding rate of a $3 \mathrm{~cm}$ basslet was over $60 \%$ higher Ultimately, such a strong effect may regulate fairy basslet populations by leading to density-dependent changes in demographic rates. Strong intraspecific competition for food can indirectly regulate adult populations of damselfish by affecting growth rate and maturation time (Jones 1987, 1990, Forrester 1990, Jones \& Hixon unpubl.). Indirect density regulation could occur in fairy basslets if larger individuals negatively affect the rates at which smaller fish grow and mature. Intense competition could also lead directly to density-dependent changes in demographic rates by influencing immigration and emigration, or by increasing susceptibility to predators. We are currently investigating such possibilities.

Acknowledgements. We are very grateful to A. Kaltenberg, who was instrumental in gathering the data for this study. M. $\mathrm{H}$. Carr also kindly assisted with fieldwork, and T. W. Anderson, G. R. Almany, T. L. Freidenburg, and E. J. Kast provided constructive comments on the manuscript. Many thanks to the staff of the Caribbean Marine Research Center. Funded by the following grants to M.A.H.: OCE-92-17163 and OCE96-17483 from the National Science Foundation; and CMRC94-15 and CMRC-97-3109 from the National Undersea Research Program. M.S.W. was partially funded by an NSF Pre-Doctoral Fellowship

\section{LITERATURE CITED}

Asoh K (1992) Reproductive biology of the fairy basslet, Gramma loreto Poey. Master's thesis, University of Puerto Rico, Mayaguez

Betram BCR (1978) Living in groups: predators and prey. In: Krebs JR, Davies NB (eds) Behavioural ecology: an evolutionary perspective. Sinauer Associates Inc, Sunderland MA, p 64-96 
Böhlke JE, Chaplin CG (1993) Fishes of the Bahamas and adjacent tropical waters. University of Texas Press, Austin, TX

Booth DJ (1991) Larval settlement and juvenile group dynamics in the domino damselfish (Dascyllus albisella). $\mathrm{PhD}$ thesis, Department of Zoology, Oregon State University, Corvallis, OR

Booth DJ (1995) Juvenile groups in a coral-reef damselfish: density-dependent effects on individual fitness and population demography. Ecology 76:91-106

Coates D (1980) Prey-size intake in humbug damselfish, Dascyllus aruanus (Pisces, Pomacentridae) living within social groups. J Anim Ecol 49:335-340

Doherty PJ (1981) Coral reef fishes: recruitment-limited assemblages? Proc 4th Int Coral Reef Symp 2:465-470

Doherty PJ (1982) Some effects of density on the juveniles of two species of tropical, territorial damselfishes. J Exp Mar Biol Ecol 65:249-261

Doherty PJ, Williams DM (1988) The replenishment of coral reef fish populations. Oceanogr Mar Biol Annu Rev 26: $487-551$

Ebeling AW, Hixon MA (1991) Tropical and temperate reef fishes: comparison of community structures. In: Sale PF (ed) The ecology of fishes on coral reefs. Academic Press, San Diego, CA, p 509-563

Forrester GE (1990) Factors influencing the demography of a coral reef fish. Ecology 71:1666-1681

Forrester GE (1991) Social rank, individual size and group composition as determinants of food consumption by the humbug damselfish, Dascyllus aruanus. Anim Behav 42: 701-711

Freeman S, Alevizon W (1983) Aspects of territorial behavior and habitat distribution of the fairy basslet Gramma loreto. Copeia 1983:829-832

Hobson ES (1991) Trophic relationships of fishes specialized to feed on zooplankters above coral reefs. In: Sale PF (ed) The ecology of fishes on coral reefs. Academic Press, New York, p 69-95

Hobson ES, Chess JR (1978) Trophic relationships among fishes and plankton in the lagoon at Enewetak Atoll, Marshall Islands. Fish Bull 76:133-153

Jenkins TM (1969) Social structure, position choice and microdistribution of two trout species (Salmo trutta and

Editorial responsibility: Otto Kinne (Editor), Oldendorf/Luhe, Germany
Salmo gairdneri) residents in mountain streams. Anim Behav Monogr 2:57-123

Jones GP (1987) Competitive interactions among adults and juveniles in a coral reef fish. Ecology 68:1534-1547

Jones GP (1990) The importance of recruitment to the dynamics of a coral reef fish population. Ecology 71:1691-1698

Jones GP (1991) Postrecruitment processes in the ecology of coral reef fish populations: a multifactorial perspective. In: Sale PF (ed) The ecology of fishes on coral reefs. Academic Press, San Diego, CA, p 294-328

Koebele BP (1985) Growth and the size hierarchy effect: an experimental assessment of three proposed mechanisms; activity differences, disproportional food acquisition, physiological stress. Environ Biol Fishes 12:181-188

Luckhurst BE, Luckhurst K (1977) Recruitment patterns of coral reef fishes on the fringing reef of Curaçao, Netherlands Antilles. Can J Zool 55:681-689

Mangel M (1990) Resource divisibility, predation and group formation. Anim Behav 39:1163-1172

Pitcher TJ, Parrish JK (1993) Functions of shoaling behaviour in teleosts. In: Pitcher TJ (ed) Behaviour of teleost fishes. Chapman and Hall, New York, p 363-439

Randall JE (1967) Food habits of the reef fishes of the West Indies. Stud Trop Oceanogr 5:665-847

Robertson DR (1996) Interspecific competition controls abundance and habitat use of territorial Caribbean damselfishes. Ecology 77:885-899

Robertson DR (1998) Implications of body size for interspecific interactions and assemblage organization among coralreef fishes. Aust J Ecol 23:252-257

Rubenstein DI (1978) On predation, competition, and the advantages of group living. In: Bateson PPG, Klopfer PH (eds) Perspectives in ethology, Vol 3. Plenum Press, New York, p 205-231

Schoener TW (1983) Field experiments in interspecific competition. Am Nat 122:240-285

Shulman M (1985) Coral reef fish assemblages: intra- and interspecific competition for shelter sites. Environ Biol Fishes 13:81-92

Smith CL, Tyler JC (1972) Space resource sharing in a coral reef fish community. Bull Nat Hist Mus Los Angeles Co 14: $125-170$

Submitted: June 23, 1999; Accepted: October 13, 1999 Proofs received from author(s): March 20, 2000 